\title{
Comparison of ANN and ANFIS Methods for the Voltage- Drop Prediction on an Electric Railway Line
}

\author{
IIlhan Kocaarslan' ${ }^{1}$, Mehmet Taciddin Akçay² ${ }^{D}$, Abdurrahim Akgündoğdu' ${ }^{1}$, Hasan Tiryaki ${ }^{1}$
}

'Department of Electrical and Electronics Engineering, İstanbul University School of Engineering, İstanbul, Turkey

2Diroctorate of Rail System, İstanbul Metropolitian Municipality, İstanbul, Turkey

Cite this article as: I. Kocaarslan, M. T. Akçay, A. Akgündoğdu, H. Tiryaki. "Comparison of ANN and ANFIS Methods for the Voltage-Drop Prediction on an Electric Railway Line". Electrica, vol. 18, no. 1, pp. 26-35, 2018.

\section{ABSTRACT}

Railway electrification systems are designed with regard to the operating data and design parameters. The minimum voltage rating required by traction during the operation should be provided. The maximum voltage drop on a line determines the minimum traction voltage. This voltage should be maintened within certain limits for the continuity of operation. In this study, the maximum voltage drop generated via traction was determined using artificial neural network (ANN) and adaptive neuro-fuzzy inference system (ANFIS) for a 25-kV AC-supplied railway. The voltage drop on line was calculated with regard to the operating data using ANN and ANFIS. ANN and ANFIS were explained, and the results were compared. The Levenberg-Marquardt (LM) algorithm was used for the ANN model. The LM algorithm is preferred because of the speed and stability it provides for the training of ANNs. The data created for one-way supply status were examined for simulation.

Keywords: ANFIS, ANN, electrification, railway, traction

Address for Correspondence:

Mehmet Taciddin Akcay

\section{E-mail:}

taciakcay@gmail.com

Received: 24.06 .2017

Accepted: 21.09 .2017

(c) Copyright 2018 by Electrica

Available online at

http://dergipark.gov.tr/iujeee

DOI: 10.5152/iujeee.2018.1805

\section{Introduction}

Mostly $25 \mathrm{kV} 50 \mathrm{~Hz}$. single-phase supply voltage is used for the traction force system on AC supplied railways. The single-phase supply voltage that the traction force uses is acquired through an interconnected network which has $154 \mathrm{kV}$ phase to phase voltage. Two transformers of $154 \mathrm{kV} / 25 \mathrm{kV}$ are present in the substations and the transformers can operate as back-up [1-6]. The equivalent circuit model of the AC railway is presented in Figure 1.

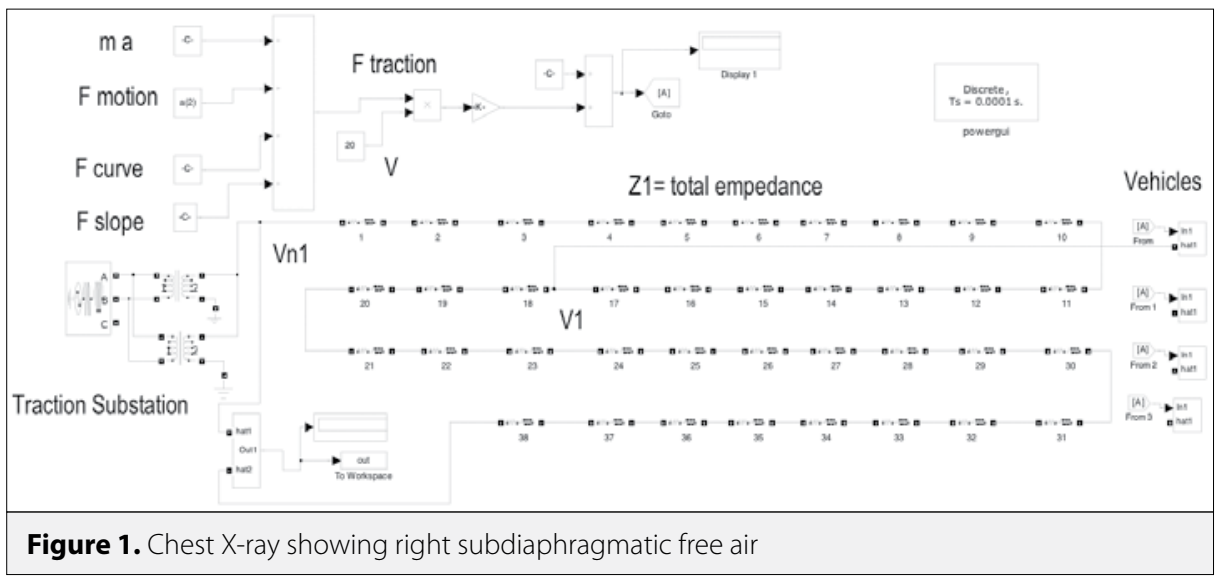

The equation regarding the supplying status from a single substation is given with Equation (1) which represents the total impedance from substation $Z 1$ to the vehicle. The impedance values of the feeder cables were also added to Z1. Z1 value changes in accordance with the distance depending on the location of the vehicle. $\mathrm{V} 1$ is the voltage of the vehicle, $\mathrm{Vn} 1$ indicates the nominal 
supply voltage, $I_{\text {vehicle }}$ indicates the vehicle current. The maximum traction force of the vehicles in the railway vehicles with a high power consumption can increase to 20 MVA [7-11].

$V_{1}=V_{n 1}-I_{\text {vehicle }} \times Z 1$

Neutral zones increase the operating capability by allowing to be supplied from different zones. Since the voltage drop occurring on the line and the currents drawn do not reach high values under normal operating conditions, the distances between the supply stations may be longer. As the number of traction supply stations and the efficiency of the traction force system increase, the voltage drop on the line and the losses decrease [12-16]. The traction system of the railway vehicle consists of a transformer, a three-phase PWM inverter and an asynchronous engine. In the course of regenerative braking, the asynchronous engine can function as a generator and enables energy transfer. This gain is more effective with the developed power electronics technology. With new research and studies, new traction force converters, various electric equipment used in railway vehicles also undergo a change [17-20]. The single-line scheme of the traction force supply diagram of an AC supplied railway is displayed in Figure 2.

The vehicle traction force $\left(\mathrm{F}_{\text {traction }}\right)$ consists of the sum of the re-

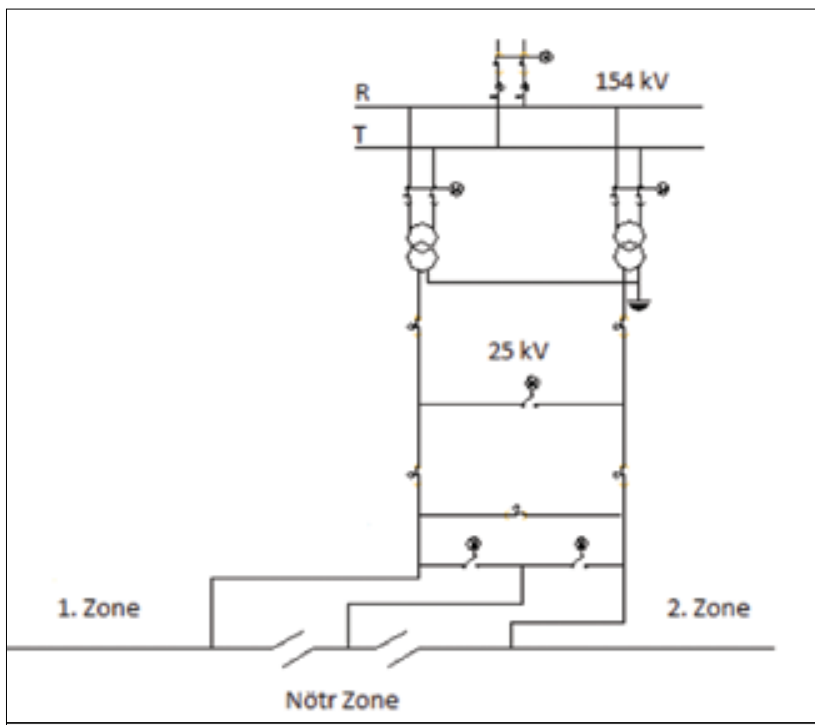

Figure 2. Single-Line scheme of the traction force supply diagram

sistance force against vehicle motion $\left(F_{\text {motion }}\right)$, slope resistance force $\left(\mathrm{F}_{\text {slope }}\right)$, curve resistance force $\left(\mathrm{F}_{\text {curve }}\right)$ and the multiplication of acceleration and mass of the vehicle, which are given with (2), (3), (4) and (5). In the equations, $V$ is the vehicle speed, $m$ is the vehicle mass, $A, B, C$ are the coefficients related to the vehicle characteristic, $g$ is the gravitational acceleration, $\mathbf{v}$ is the angle of inclination, $\mathrm{R}$ is the curve radius, C1, C2 and C 3 are the coefficients used to calculate the curve force. In equation (5), the acceleration-mass (ma) value expresses the net force that affects the vehicle. The power equation of the vehicle is given with regard to the traction force and vehicle speed by Equation (6).

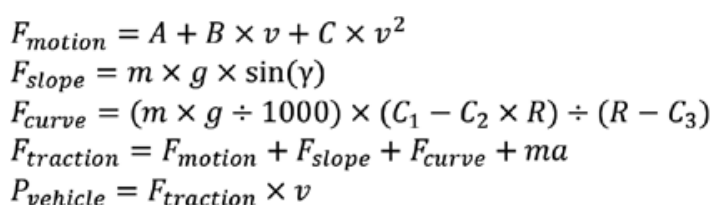

The vehicle power increases with the traction force and vehicle speed. The equivalent circuit given with Figure 1 was simulated with different operating parameters and 1000 data arrays were obtained regarding different operating conditions. Equations 1-6 were used to obtain different simulation datas given with Figure 1. 1000 simulation was done with different operation parameters for the best result for the prediction. The parameters used in the simulation are the number of vehicles, acceleration-mass value of the vehicle, vehicle motion resistance, curve radius, slope, the length of the supply line, internal consumption current of the vehicle, electric resistance and inductance of the line; the calculated value is the highest voltage drop value occurring on the line. Random values were assigned to all the input parameters used in the simulation. For the simulation, the number of vehicles varying between $0-10$ was used and the vehicle placement was performed by taking the maximum voltage drop into consideration. The diversity of the parameters and the variability in operating conditions in the simulation render the solution of this problem complex. Artificial Intelligence is the science which deals with enabling machines to produce solutions to complex problems as humans. This is generally performed by taking the characteristic of human intelligence and applying it to the computer as an algorithm. In accordance with the demanded or desired needs, which mental attitude will be presented to which effect, less or more flexible or effective approaches can be displayed. Artificial intelligence was preferred in this study due to the stated advantages.

\section{Material and Method}

In this study, the artificial neural network and adaptive fuzzy inference system among the artificial intelligence applications were used for simulation. The ANN is a method which functions by imitating the way of work of a simple biological nervous system. The ANFIS is a hybrid artificial intelligence method which uses the parallel computing and learning capability of artificial neural networks and the inferential characteristic of fuzzy logic. Matlab program was used for simulations.

\section{Artificial Neural Networks (ANN)}

Artificial neural networks emerged as a mathematical method from the latest outputs of endeavors to study and imitate human nature. Artificial neural networks take computing and data processing power from their parallel distributed structure, their capability to learn and generalize. Generalisation is defined as artificial neural networks' producing proper reactions to the inputs which have not been experienced in the course of education or learning. These characteristics indicate the problem-solving capability of artificial neural networks [21-24]. 
The biological neuron consists of a nucleus, body and two extensions. The structure of the artificial neural network is given in Figure 3. The $1^{\text {st }}$ layer is the input layer. Data are received from here and entered into the system. The $2^{\text {nd }}$ layer is the hidden layer. Its use depends on the simulation. The $3^{\text {rd }}$ layer is the output layer. Inputs are processed and received from here. Each sphere (nerve) has a function and a threshold value. Filled small circles indicate bonding weights [25-30].

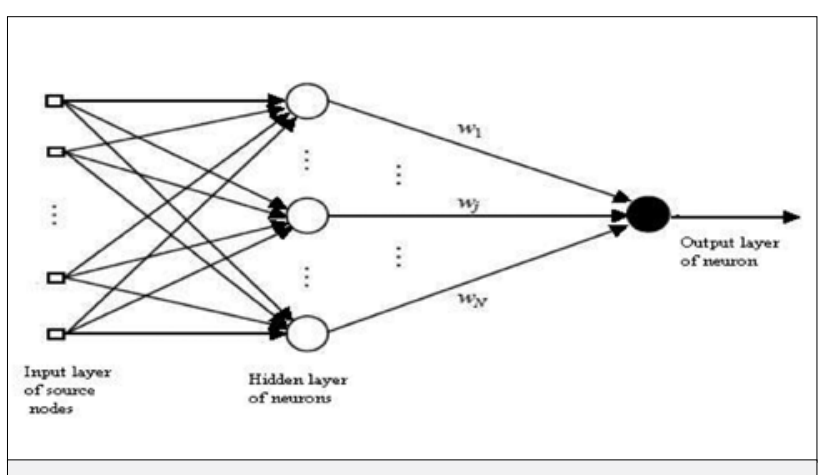

Figure 3. The structure of the artificial neural network

\section{Levenberg-Marquardt Algorithm}

The Levenberg-Marquardt algorithm is a least squares computing method based on the maximum neighborhood. This algorithm consists of the best features of the Gauss-Newton and gradient-descent algorithms and removes the restrictions of these two methods. This method is not affected by the slow convergence problem. The Levenberg-Marquart algorithm, which is the combination of the Gauss-Newton algorithm, is more efficient and rapid in optimization problems when compared to the sloping downward algorithm [25].

\section{Adaptive Neuro Fuzzy Inference System (ANFIS)}

The ANFIS is a class of adaptive networks functionally equivalent to the fuzzy inference system. The ANFIS can be given more integrated with some characteristics of controllers, learning ability, parallel processing, structured knowledge representation, other supervision and design methods. Fuzzy logic and neural networks are supplementary means used together in developing smart systems [31-34]. The ANFIS consists of 6 layers. This system is displayed in Figure 4. The node functions of every layer in the ANFIS structure and the operation of the layers are respectively as follows [34]. First layer is named the input layer. The input signals obtained from every node in this layer are transmitted to other layers. Second layer is named the fuzzification layer. In separating the input values into fuzzy sets, Jang's ANFIS model uses the Bell activation function generalized as a membership function. Here, the output of each node consists of membership degrees based on the input values and the membership function used and the membership values obtained from the $2^{\text {nd }}$ layer are presented as and Third layer is the layer of rules. Each node in this layer expresses the rules established in accordance with the Sugeno fuzzy logic inference system and their number. The output of each rule node $\mathrm{m}$ turns out to be the multiplication of membership degrees which arrive from the 2 nd layer. The acquisition of $m_{1}$ values, on the condition that $(j=1,2)$ and $(i=1, \ldots, n)$, is as follows:

$$
y_{i}{ }^{3}=\Pi_{i}=\mu_{A_{j}}(x) \times \mu_{B_{j}}(y)=\mu_{i}
$$

Here, represents the output values of the 3rd layer; $n$ represents the number of nodes in this layer. Fourth layer is the normalization layer. Each node in this layer regards all the nodes coming from the rule layer as input values and computes the normalized ignition level of each rule. The computing of the normalized ignition level is performed in accordance with the following formula:

$$
y_{i}{ }^{4}=N_{i}=\frac{\mu_{i}}{\sum_{i=1}^{n} \mu_{i}}=\overline{\mu_{i}}(\mathrm{i}=1, \mathrm{n})
$$

Fifth layer is the purification layer. The weighted resulting values of a given rule in each node in the purification layer are calculated. The output value of the $\mathrm{i}^{\text {th }}$ node in the $5^{\text {th }}$ layer is as follows.

$$
y_{i}^{5}=\overline{\mu_{i}}\left[p_{i} x_{1}+q_{i} x_{2}+r_{i}\right], \quad(\mathrm{i}=1, \mathrm{n})
$$

The (pi , qi , ri ) variables here are the outcome parameter set of the ith rule. Sixth is the sum layer. There is only one node in this layer and it is labeled as $\Sigma$.The output value of each node in the 5th layer is summed here so that the actual value of the ANFIS system is obtained. The computing of $y$, which is the output value of the system, is performed in accordance with the equation below [31].

$$
y=\sum_{i=1}^{n} \overline{\mu_{i}}\left[p_{i} x_{1}+q_{i} x_{2}+r_{i}\right]
$$

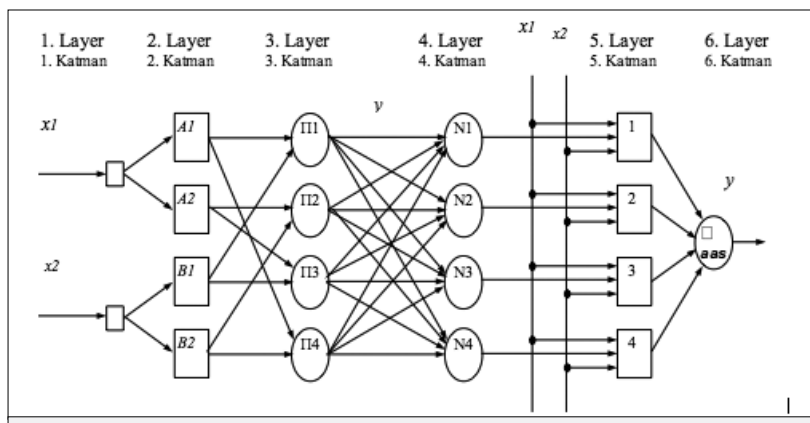

Figure 4. ANFIS structure

\section{Mean absolute error (MAE)}

The mean absolute error is the division of the absolute value of the difference between the measured values and predicted values by the measurement number. It is given by Equation (11), $\mathrm{n}$ represents the measurement number, e represents the difference between the actual value and estimated value [35-36].

$$
M A E=\frac{1}{n} \sum_{i=1}^{n}\left|e_{i}\right|
$$

\section{Root mean squared error (RMSE)}

The Root Mean Squared Error is acquired by dividing the real error sum of squares of a measuring line by the measurement number and by taking the square root of this calculated value. It carries out the most correct approach regarding the degree of accuracy of the measurements. In the RMSE equation given 
by equation (12), xobs are the real values, xmodel are the predicted values, $\mathrm{n}$ is the measurement number [35-36].

$$
R M S E=\sqrt{\frac{\sum_{i=1}^{n}\left(X_{o b s, i}-X_{\text {model }, i}\right)^{2}}{n}}
$$

\section{Relative absolute error (RAE)}

The Relative absolute Error is acquired by dividing the sum of real error of a measuring line by the sum of predicted error. In the RAE equation given by equation (13), xobs are the real values, $x$ model are the predicted values, model is the mean value of $x$ model, $n$ is the measurement number [35-36].

$$
R A E=\frac{\sum_{i=1}^{n}\left|X_{\text {obs }, i}-X_{\text {model }, i}\right|}{\sum_{i=1}^{n}\left|\bar{X}_{\text {model }, i}-X_{\text {model }, i}\right|}
$$

\section{Root relative squared error (RRSE)}

The Root relative squared error is acquired by dividing the real error sum of squares of a measuring line by the predicted error sum of squares and by taking the square root of this calculated value. In the RRSE equation given by equation (14), xobs are the real values, xmodel are the predicted values, model is the mean value of $x$ model, $n$ is the measurement number $[35,36]$.

$$
R R S E=\sqrt{\frac{\sum_{i=1}^{n}\left(X_{\text {obs }, i}-X_{\text {model }, i}\right)^{2}}{\sum_{i=1}^{n}\left(\bar{X}_{\text {model }, i}-X_{\text {model }, i}\right)^{2}}}
$$

\section{Findings}

1000 data arrays different from each other were used for the calculation of the voltage drop created by the traction force. A portion of the data used is displayed in Table 1.

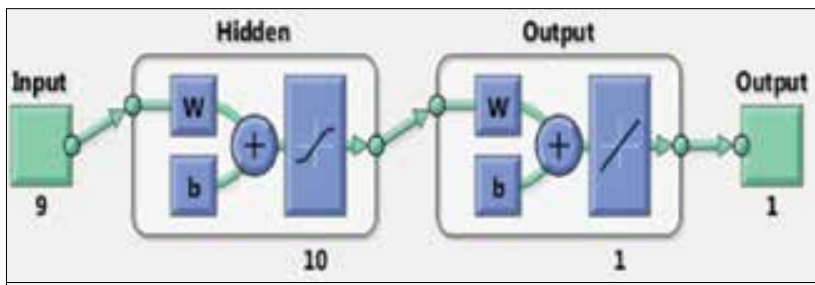

Figure 5. ANN architecture designed [MATLAB R2015b]

\section{Simulation results with the ANN}

As seen in Table 1, the system consists of 9 input and 1 output parameters. The ANN architecture used is given in Figure 5.

9 input data, 10 hidden neurons, 1 output neuron and 1 output data were used for the ANN architecture used in the design. $70 \%$ of the data used for simulation were used for education, $15 \%$ for validation, $15 \%$ for the test. As seen in Figure 6 , the best validation value was reached at the $49^{\text {th }}$ iteration by inhibiting overfitting in the simulation. The lowest mean squared error value is 152241.40 . The training, validation and test data produced by the system displayed similar characteristics. Since the validation error value increased in the course of 6 iterations, the simulation was stopped at the end of 55 iterations.

The backpropagation gradient value is given on a logarithmic scale for each iteration with Figure 7. The difference between the test values and validation values is predicted. Validation checks and Matlab stop the simulation with the increase in the mse value of the validation values in order to inhibit overfitting at the end of 6 iterations. The mse performance is given with the training state graph. Gradient $=718660.15$ at epoch 55, $\mathrm{mu}=1000$ at epoch 55 and the validation checks $=6$ at epoch 5 .

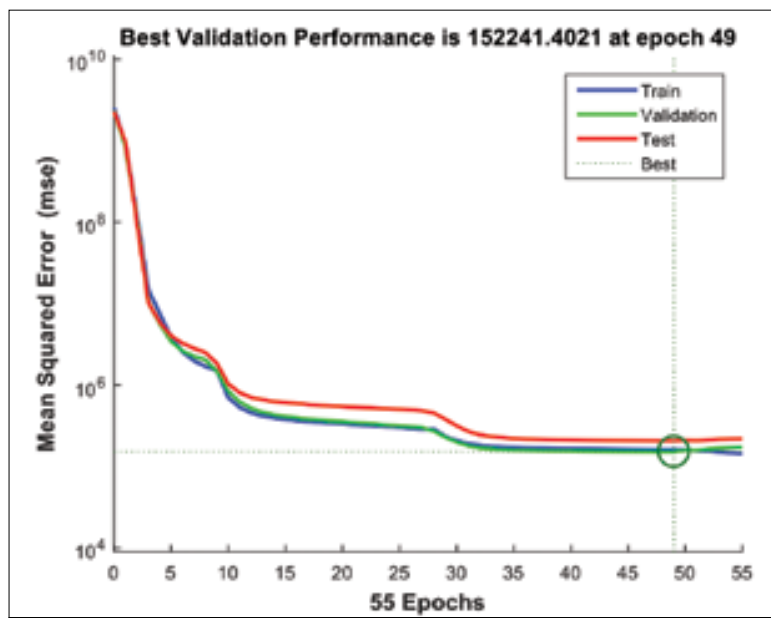

\begin{tabular}{|c|c|c|c|c|c|c|c|c|c|c|}
\hline Inputs & $\begin{array}{c}\text { Output } \\
\text { Number } \\
\text { of } \\
\text { vehicles }\end{array}$ & $\begin{array}{c}\text { Ma value } \\
\text { (kilonewton) }\end{array}$ & $\begin{array}{c}\text { Vehicle } \\
\text { motion } \\
\text { resistance } \\
\text { (kilonewton) }\end{array}$ & $\begin{array}{l}\text { Curve } \\
\text { radius } \\
\text { (meter) }\end{array}$ & Slope & $\begin{array}{c}\text { The length } \\
\text { of the } \\
\text { supply line } \\
\text { (kilometer) }\end{array}$ & $\begin{array}{l}\text { Internal } \\
\text { consumption } \\
\text { current of } \\
\text { the vehicle } \\
\text { (amper) }\end{array}$ & $\begin{array}{l}\text { Line } \\
\text { resistance } \\
\text { (ohm) }\end{array}$ & $\begin{array}{c}\text { Line } \\
\text { inductance } \\
\text { (henry) }\end{array}$ & $\begin{array}{c}\text { Voltage } \\
\text { drop } \\
\text { (volt) }\end{array}$ \\
\hline 6 & 235 & 65 & 910 & 0.0054 & 72 & 19.1 & 0.1271 & 0.001273 & 23525 & \\
\hline 9 & 279 & 80 & 866 & 0.0177 & 68 & 19.1 & 0.1416 & 0.00146 & 46809 & \\
\hline 2 & 210 & 65 & 890 & 0.0312 & 46 & 19.9 & 0.1236 & 0.001298 & 8100 & \\
\hline 1 & 215 & 68 & 908 & 0.0292 & 96 & 22.3 & 0.1225 & 0.001272 & 11142 & \\
\hline 1 & 223 & 69 & 939 & 0.0371 & 36 & 21.8 & 0.1107 & 0.001117 & 4022 & \\
\hline
\end{tabular}

Figure 6. Best validation performance graph

Table 1. A portion of the data set that used 


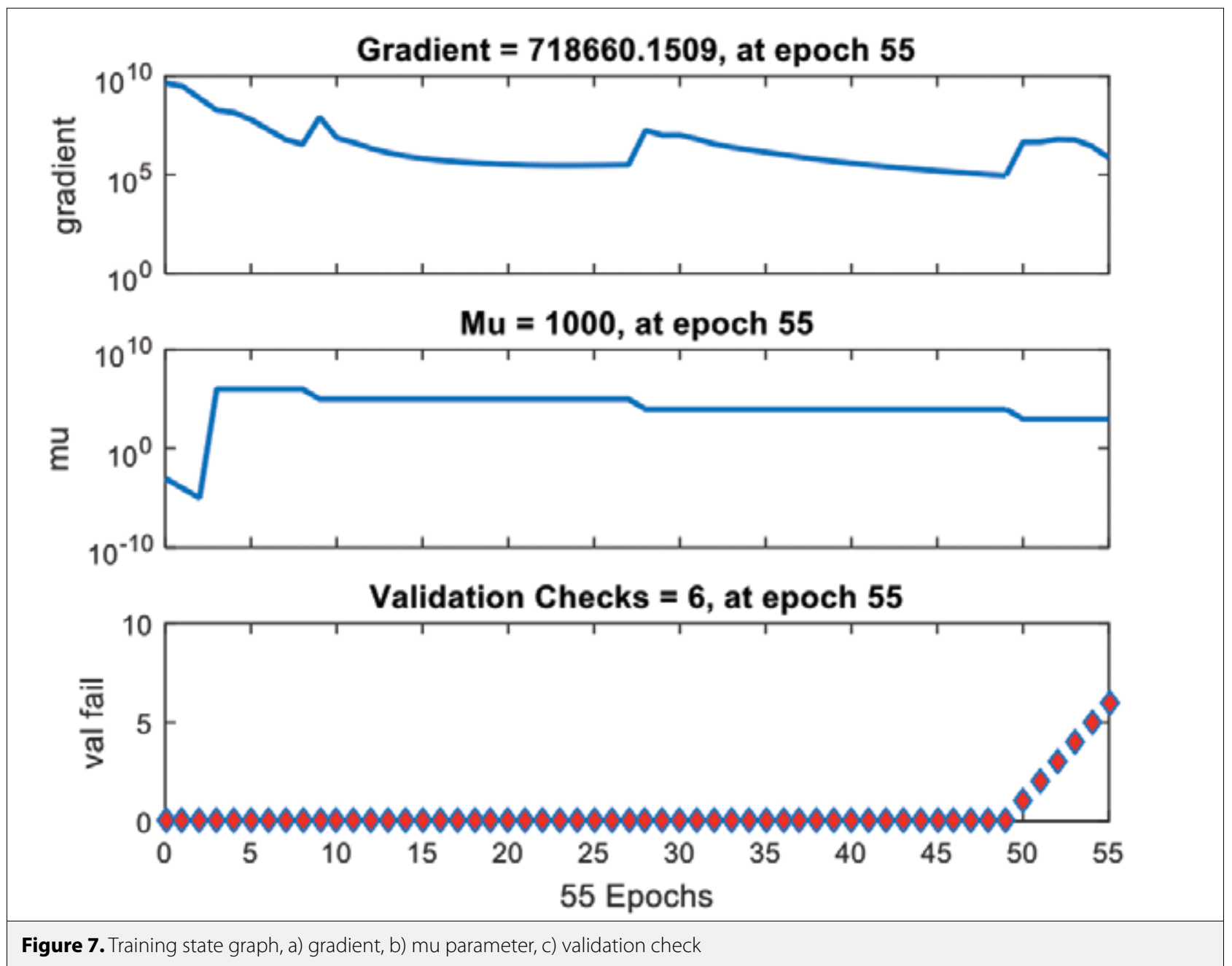

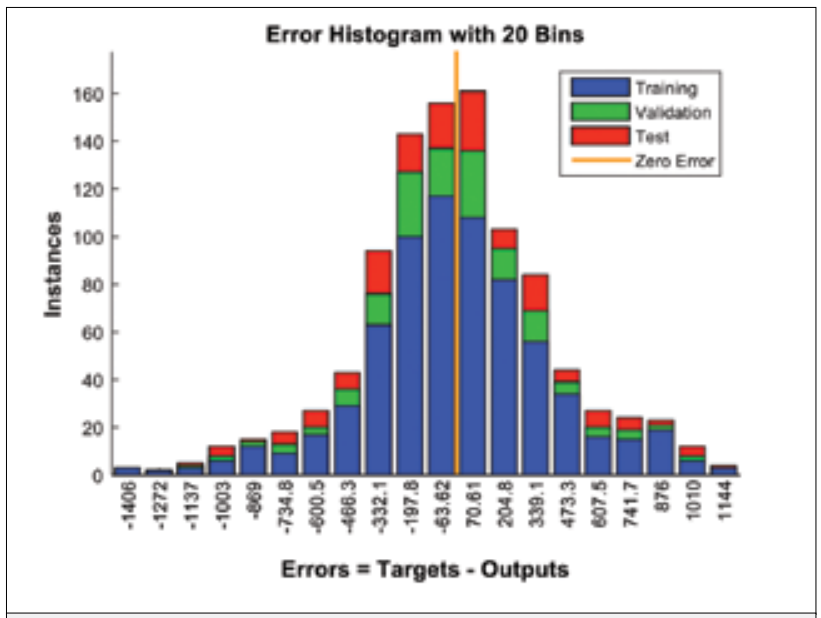

Figure 8. ANN Error histogram

The error histogram of ANN simulation is shown in Figure 8. The differences between the realized values and calculated values are seen with this graph. The distribution of the errors of the training data is shown with blue, validation data with green and test data with red. The errors mostly concentrate between -1137 and 1010 .
The realized and calculated values of the training, validation and test data are seen in Figure 9. The regression value is shown with $\mathrm{R}$, and as seen in the Figure 9, these values are 0.99962 for training, 0.9996 for validation, 0.99936 for the test data. The $\mathrm{R}$ value is 0.99959 for all data. As this value approaches 1 , the accuracy of the data calculated by the system increases.

The realized data, calculated data and error values are shown in Figure 10. The realized data are given with blue, the calculated data are given with red, error values are given with yellow.

\section{Simulation results with the ANFIS}

The structure of the system created for the ANFIS and the simulation results are given below. A structure with 9 inputs 2 membership functions created for the ANFIS is given with Figure 11. $70 \%$ of the data used for simulation were used for education, $15 \%$ for validation, $15 \%$ for the test. A triangular-shaped membership function was used for the simulation.

Some of the rules established for the ANFIS are shown in Figure 12. $2^{9}=512$ rules were established for the ANFIS design. 
a

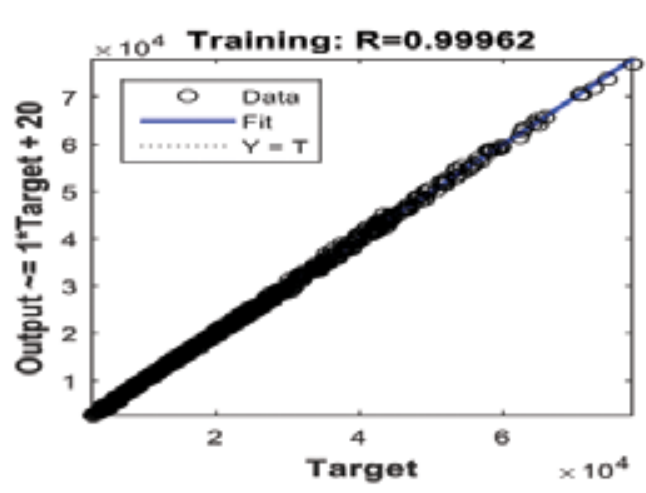

c

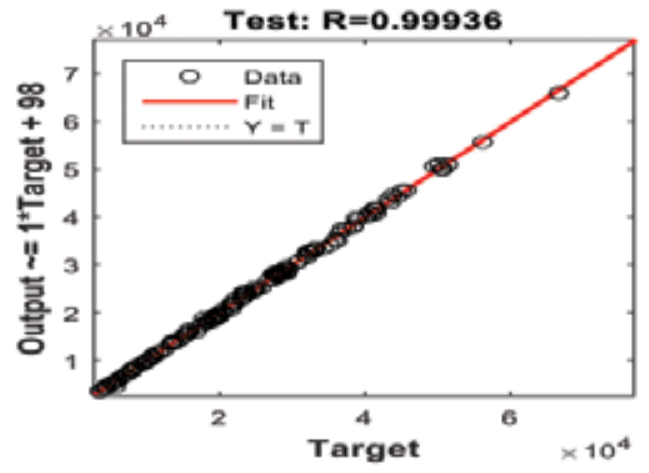

b

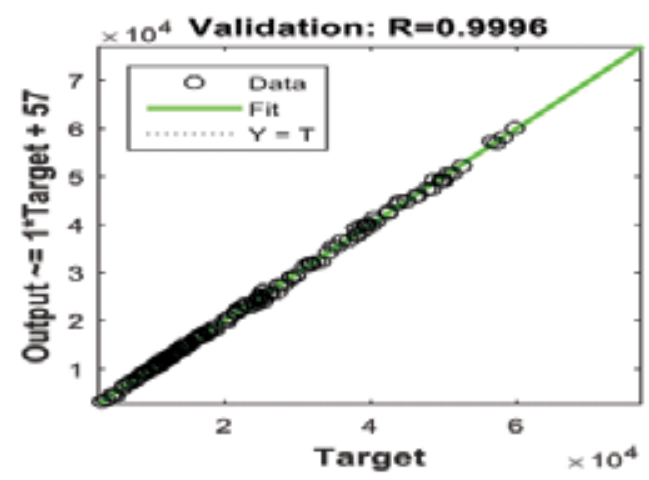

d

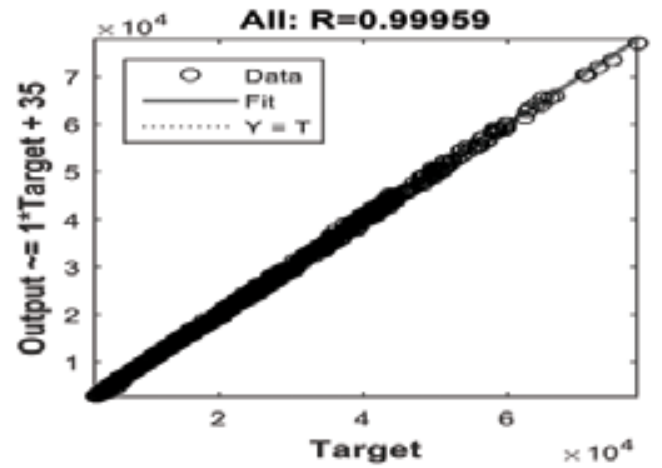

Figure 9. ANN regression graph, a) training, b) validation, c) test, d) all

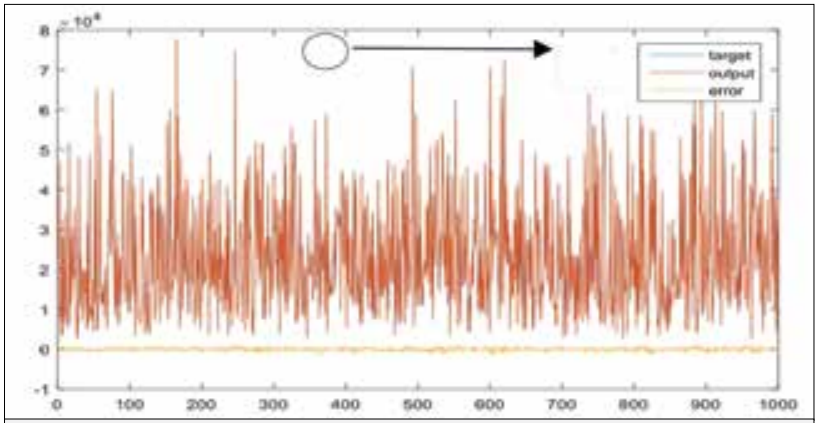

Figure 10. Output, prediction and error data graph of the YSA simulation

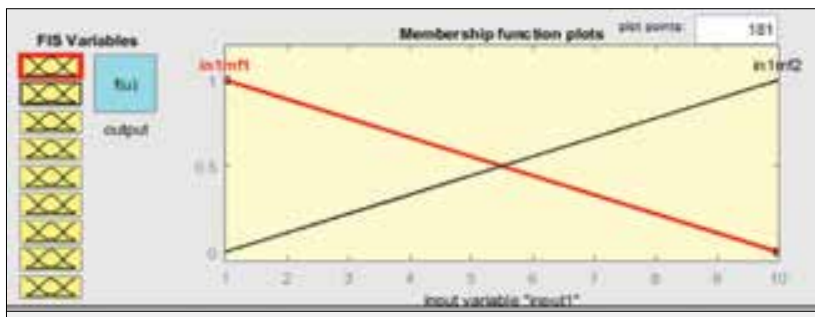

Figure 11. Triangular-shaped membership function

The ANFIS architecture is shown in Figure 13. The system consists of the input, input MF, Rule, output MF and output modules.

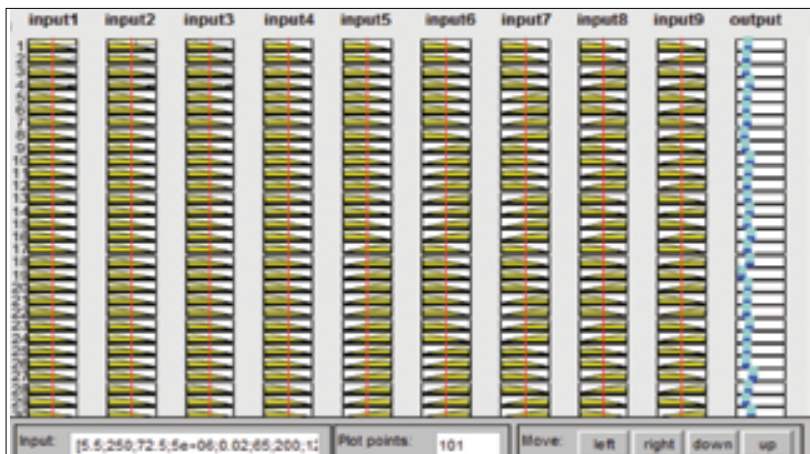

Figure 12. Rules established for the ANFIS

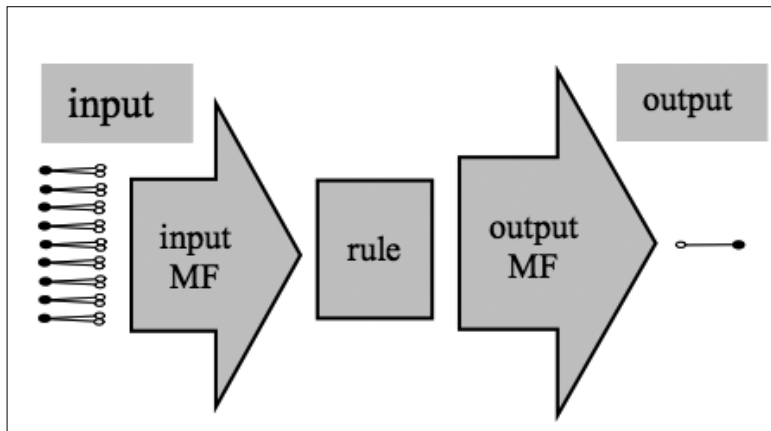

Figure 13. ANFIS architecture 
The error histogram of ANFIS simulation is shown in Figure 14. The differences between the realized values and calculated values are seen with this graph. The distribution of the errors of

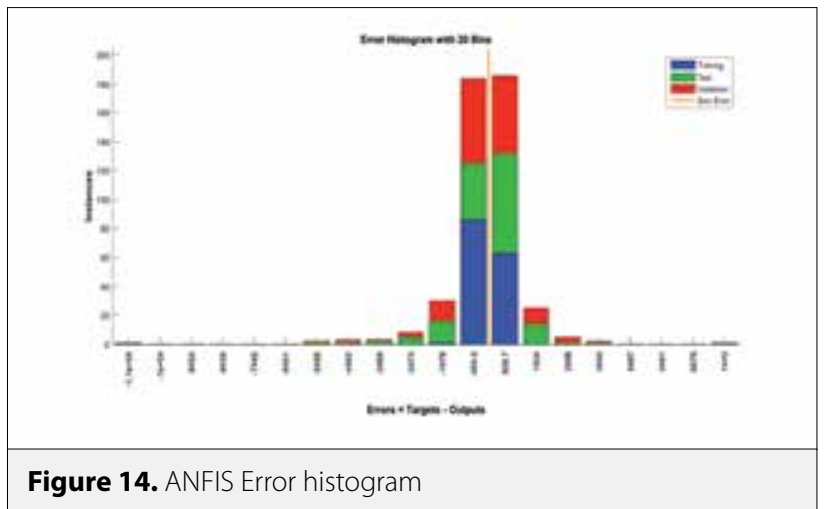

the training data is shown with blue, validation data with red and test data with green. The errors mostly concentrate between -5456 and 3493.

The realized and calculated values of the training, validation and test data for ANFIS simulation are seen in Figure 15. The regression value is shown with $\mathrm{R}$, and as seen in the Figure 15, these values are 0.99989 for training, 0.99685 for validation, 0.99425 for the test data. The $\mathrm{R}$ value is 0.99844 for all data. As this value approaches 1 , the accuracy of the data calculated by the system increases.

The realized data, calculated data and error data are shown in Figure 16.
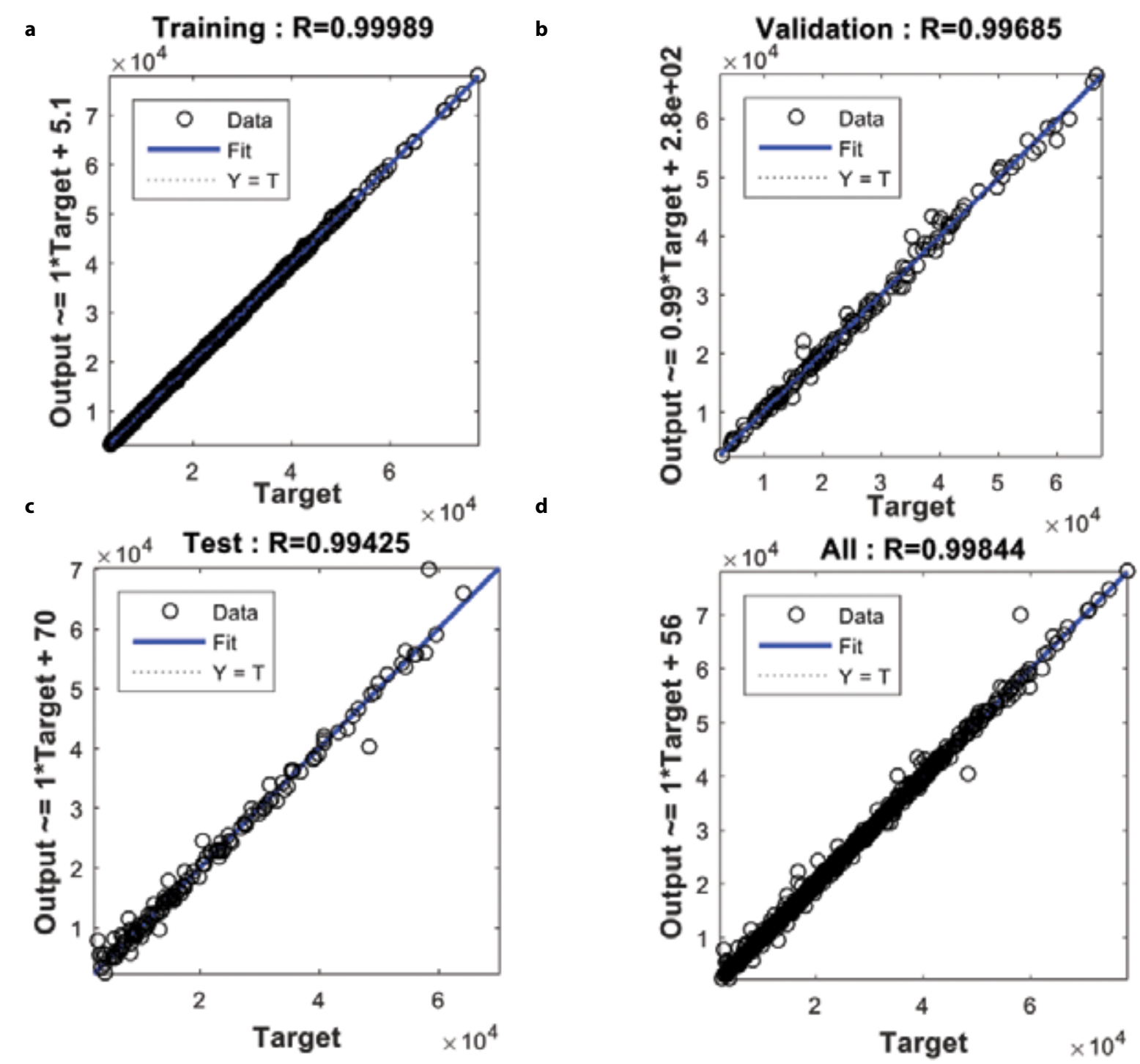

Figure 15. ANFIS regression graph, a) training, b) validation, c) test, d) all 


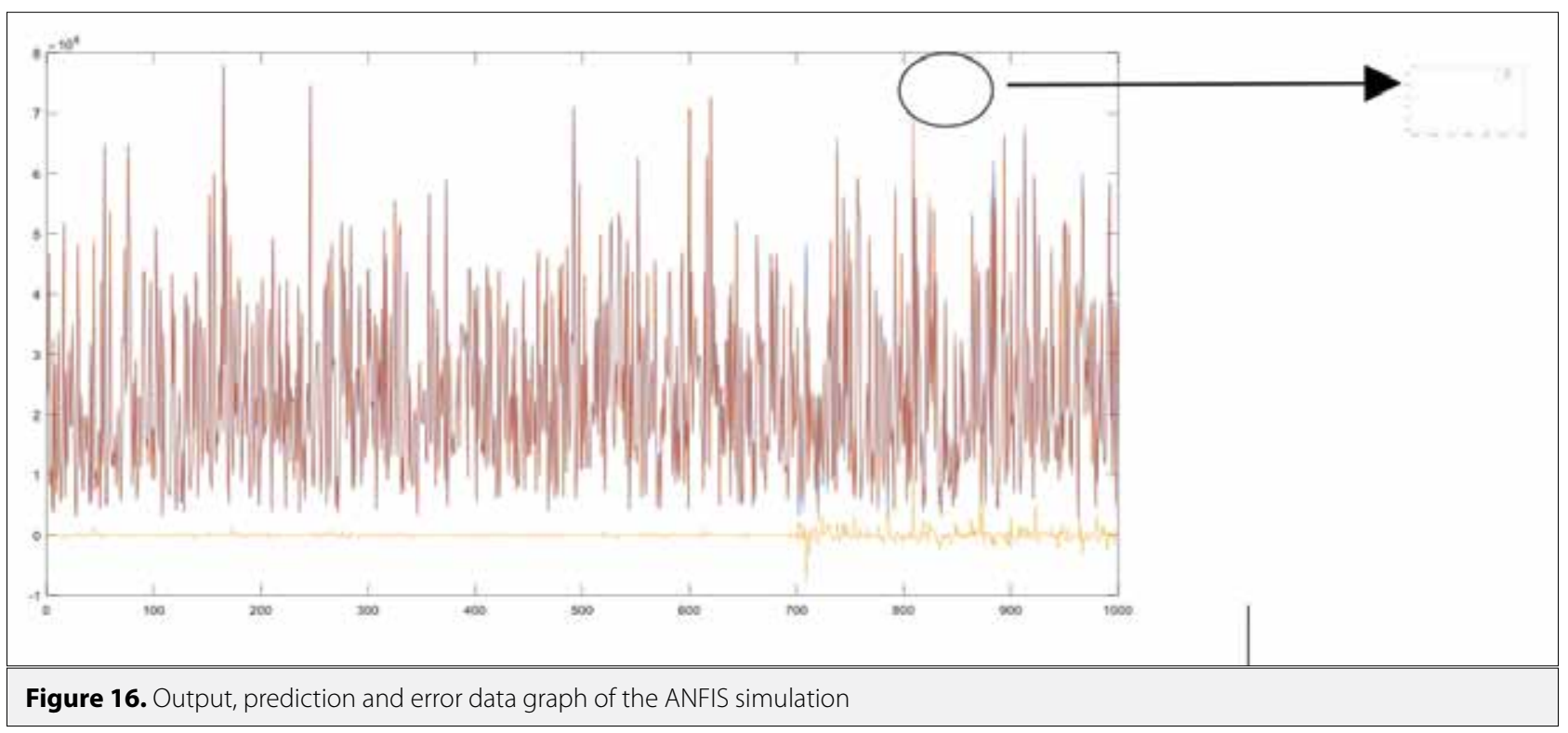

Table 2. The simulation results of both methods

\begin{tabular}{lcc}
\hline Method & ANN & ANFIS \\
\hline Mean absolute error (MAE) & 305.3448 & 339.1464 \\
\hline Root mean squared error (RMSE) & 407.4496 & 792.9189 \\
\hline Relative absolute error (RAE) & 0.0266 & 0.0295 \\
\hline Root relative squared error (RRSE) & 0.0288 & 0.0560 \\
\hline Total Number of Instances & 1000 & 1000 \\
\hline ANN: artificial neural network; ANFIS: adaptive neuro-fuzzy inference system
\end{tabular}

\section{The comparison of the ANN and ANFIS results}

When the ANN and ANFIS results are compared, the ANFIS results are observed to be better. The simulation results of both methods are given in Table 2 .

\section{Conclusions}

In this study, the prediction of the highest voltage drop created by the traction force on an AC supplied railway with regard to the operating data was performed. 1000 random input data arrays and the calculated output data were used for the simulation. In the analyses carried out, the ANN and ANFIS techniques were used. The voltage drop value was predicted. The RRSE value in the data obtained for the ANFIS in the calculations carried out is $5.6 \%$ and this value is $2.9 \%$ in the ANN. The RMSE values are $407 \mathrm{~V}$ for the ANN simulation and $793 \mathrm{~V}$ for the ANFIS. The MAE value acquired in the ANN is $305 \mathrm{~V}$, this value is $339 \mathrm{~V}$ in the ANFIS. The RAE value in the ANN is $2.7 \%$, this value is $3 \%$ in the ANFIS. When the data obtained from the simulations are compared, the prediction values produced with the ANN are observed to be better. When the prediction data produced for both tech- niques are compared with the real data, it is observed that errors are at an acceptable rate and that the prediction data produced are usable.

\section{References}

1. J. S. Huh, H.S. Shin, W. S. Moon, B. W. Kang, J. C. Kim, "Study on voltage unbalance improvement using SFCL in power feed network with electric railway system," IEEE Transactions on Applied Superconductivity, vol. 3: 3601004, 2013.

2. A. Ghassemi, S. S. Fazel, I. Maghsoud, S. Farshad, "Comprehensive study on the power rating of a railway power conditioner using thyristor switched capacitor," IET Electrical Systems in Transportation, vol. 4, pp. 97-106, 2014. [CrossRef]

3. G. Raimondo, P. Ladoux, A. Lowinsky, H. Caron, P. Marino, "Reactive power compensation in railways based on AC boost choppers," IET Electrical Systems in Transportation, vol. 2, pp. 169-177, 2012. [CrossRef]

4. K. Aodsup and T. Kulworawanichpong, "Effect of train headway on voltage collapses in high-speed AC railways," In: APPEEC 2012 Power and Energy Engineering Conference; 27-29 March 2012; Shanghai, China. New York, USA: IEEE. pp. 1-4. [CrossRef]

5. M. A. A. Baseri, M. N. Nezhad, M. A. Sandidzadeh, "Compensating procedures for power quality amplification of AC electrified railway systems using FACTS," In: PEDSTC 2011 Power Electronics Drive Systems and Technologies Conference; 1617 Februrary 2011; Tehran, Iran. New York, USA: IEEE. pp. 518521.

6. M. Brenna and F. Foiadelli, "The compatibility between DC and AC supply of the Italian railway system," In: Power and Energy Society General Meeting; 24-29 July 2011; San Diego, USA. New York, USA: IEEE. pp. 1-7. [CrossRef]

7. L. Abrahamsson, T. Kjellqvist, S. Ostlund, "High-voltage DC-feeder solution for electric railways," IET Power Electronics, vol. 5, pp. 17761784, 2012. [CrossRef]

8. S. V. Raygani, A. Tahavorgar, S. S. Fazel, B. Moaveni, "Load flow analysis and future development study for an AC electric railway," IET Electrical Systems in Transportation, vol. 2, pp. 139-147, 2012. [CrossRef] 
9. C. J. Goodman and M. Chymera, "Modelling and simulation," In: REIS 2013 Railway Electrification Infrastructure and Systems Conference; 3-6 June 2013; London, England. New York, USA: IEEE. pp. 16-25. [CrossRef]

10. P. Ladoux, G. Raimondo, H. Caron, P. Marino, "Chopper-Controlled steinmetz circuit for voltage balancing in railway substations," IEEE Transactions on Power Electronics, vol. 28, pp. 58135822, 2013. [CrossRef]

11. H. S. Shin, S. M. Cho, J. C. Kim, "Protection scheme using SFCL for electric railways with automatic power changeover switch system," IEEE Transactions on Applied Superconductivity, vol. 20, 5600604, 2012.

12. H. S. Shin, S. M. Cho, J. S. Huh, J. C. Kim, D. J. Kweon, "Application on of SFCL in automatic power changeover switch system of electric railways," IEEE Transactions on Applied Superconductivity vol. 22, 5600704, 2012. [CrossRef]

13. V. Kolar, R. Hrbac, T. Mlcak T, "Measurement and simulation of stray currents caused by AC railway traction," In: EPE 2015 Electric Power Engineering Conference; 20-22 May 2015; Prague, Czech Republic. New York, USA: IEEE. pp. 764-768.

14. M. Chen, W. Jiang, J. Luo, T. Wen, "Modelling and simulation of new traction power supply system in electrified railway," In: ITSC 2015 IEEE 18th International Conference on Intelligent Transportation Systems; 15-18 September 2015; Las Palmas, Canada. New York, USA: IEEE. pp. 1345-1350. [CrossRef]

15. M. Soler, J. Lopez, J. Manuel, M. S. Pedro, J. Maroto, "Methodology for multiobjective optimization of the AC railway power supply system," IEEE Transactions on Intelligent Transportation Systems, vol. 16, pp. 2531-2542, 2015. [CrossRef]

16. Z. He, Y. Zhang, S. Gao, "Harmonic resonance assessment to traction power supply system considering train model in China highspeed railway," IEEE Transactions On Power Delivery, vol. 29, pp. 1735-1743, 2014. [CrossRef]

17. W. Song, J. Ma, L. Zhou, X. Feng, "Deadbeat predictive power control of single-phase three-level neutral-point-clamped converters using space-vector modulation for electric railway traction," IEEE Transactıons On Power Electronics, vol. 31, pp. 721-732, 2016. [CrossRef]

18. M. Shafighy, S. Khoo, A. Z. Kouzani, "Modelling and simulation of regeneration in AC traction propulsion system of electrified railway," IET Electrical Systems in Transportation, vol. 5, pp. 145-155, 2015. [CrossRef]

19. S. Kejian, W. Mingli, V. G. Agelidis, W. Hui W, "Line current harmonics of three-level neutral point-clamped electric multiple unit rectifiers: analysis," Simulation and Testing, IET Power Electronics, vol. 7, 1850-1858, 2014. [CrossRef]

20. P. Drabek, Z. Peroutka, M. Pittermann, P. Cedl, “New configuration of traction converter with medium-frequency transformer using matrix converters," IEEE Transactıons On Industrial Electronics, vol. 58, pp. 5041-5048, 2011. [CrossRef]

21. H. Ozdemir, "Artificial neural networks and their usage in weaving technology," Electronic Journal of Textile Technologies, vol. 7, pp. 5168, 2013.

22. M. Sahin, F. Buyuktumturk, Y. Oguz, "Light quality control with artificial neural networks," Afyon Kocatepe University Journal of Science and Engineering, vol. 13, vol. 1-10, 2013.
23. R. Bayindir, Ö. Sesveren, "Design of a visual interface for ANN based systems," Pamukkale University Engineering Faculty Journal of Engineering Science, vol. 14, pp. 101-109, 2008.

24. D. Askin, I. Iskender, A. Mamızadeh, "Dry type transformer winding thermal analysis usıng different neural network methods," Journal of the Faculty of Engineering and Architecture of Gazi University, vol. 26, pp. 905-913, 2011.

25. M. A. Cavuslu, Y. Becerikli, C. Karakuzu. "Hardware implementation of neural network training with levenberg-marquardt algorithm," Journal of Computer Science and Engineering, vol. 5, pp. 31-38, 2012.

26. İ. Dalkiran, K. Danisman, "Artificial neural network based chaotic generator for cryptology," Turkish Journal Of Electrical Engineering And Computer Sciences, vol. 18, pp. 225-240, 2010.

27. M. Ceylan, Y. Ozbay, O. N. Ucan, E. Yildirim, "A novel method for lung segmentation on chest ct images: complex-valued artificial neural network with complex wavelet transform," Turkish Journal Of Electrical Engineering And Computer Sciences, vol. 18, pp. 613$623,2010$.

28. S. Partal, I. Senol, A. F. Bakan, K. N. Bekiroglu, "Online speed control of a brushless AC servomotor based on artificial neural networks," Turkish Journal Of Electrical Engineering And Computer Sciences, vol. 19, pp. 373-383, 2011.

29. S. Jashfar, S. Esmaeili, M. Z. Jahromi, M. Rahmanian, "Classification of power quality disturbances using s-transform and tt-transform based on the arti_cial neural network," Turkish Journal Of Electrical Engineering And Computer Sciences, vol. 21, pp. 1528-1538, 2013. [CrossRef]

30. M. Afsharizadeh, M. Mohammadi, "Prediction-Based reversible Image watermarking using artificial neural networks," Turkish Journal Of Electrical Engineering And Computer Sciences, vol. 24, pp. 896-910, 2016. [CrossRef]

31. I. A. Ozkan, I. Saritas, S. Herdem, "Modeling of magnetic filtering with ANFIS," In: 12. National Conference on Electrical Electronic Computer Biomedical Engineering; 14-18 November 2007; Eskişehir, Turkey. Ankara, Turkey: CEE. pp. 415-418.

32. M. R. Minaz, A. Gun, M. Kurban, N. Imal, "Estimation of pressure, temperature and wind speed of bilecik using different methods," Gaziosmanpasa Journal of Scientific Research, vol. 3, pp. 100-111, 2013.

33. S. Sit, H. R. Ozcalik, E. Kilic, O. Dogmus, M. Altun, "Investigation of performance based on online adaptive neuro-fuzzy inference system (ANFIS) for speed control of induction motors," Cukurova University Journal of the Faculty of Engineering and Architecture, vol. 31, pp. 33-42, 2016.

34. J. S. R. Jang, "ANFIS: Adaptive-network-based fuzzy inference system," IEEE Transactions on Systems, Man, and Cybernetics, vol. 23, pp. 665-685, 1993. [CrossRef]

35. S. Yurtcu and A. Ozocak, "Prediction of compression index of finegrained soils using statistical and artificial intelligence methods," Journal of the Faculty of Engineering and Architecture of Gazi University, vol. 31, pp. 597-608, 2016.

36. C. J. Willmott and C. Matsuura, "Advantages of the mean absolute error (MAE) over the root mean square error (RMSE) in assessing average model performance," Climate Research, vol. 30, pp. 79-82, 2005. [CrossRef] 
Illhan Kocaarslan was born in Kırıkkale in 1964. He received his B.Sc. and first M.Sc. degrees in Electrical Engineering from Yıldız Technical University in 1983 and 1985 in Turkey, respectively. He received his second M.Sc. and Ph. D. degrees in Electrical Engineering from Bochum Ruhr University in 1986 and 1991 in Germany, respectively. He received the title of professor in 1999 in Turkey. Since 2008, he is working in Electrical-Electronics Engineering Department at İstanbul University, Turkey. His research interests are railway systems, control systems, automation, power generation, transmission and distribution.

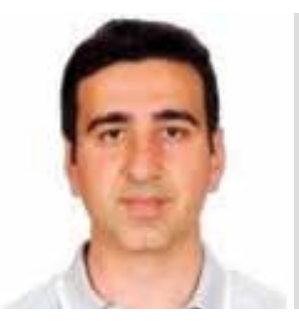

Mehmet Taciddin Akçay was born in Kilis in 1984. He received his B.Sc. degree in Electrical Engineering from İstanbul Technical University in 2007 and M.Sc. degrees in Electrical and Electronics Engineering from Sakarya University in 2010. Since 2008 he is working in İstanbul Metropolitian Municipality, Directorate of Rail Systems. Since 2011 he is Ph. D. student in Electrical-Electronics Engineering Department at İstanbul University. His research interests are railway systems, power system analysis and energy management systems.

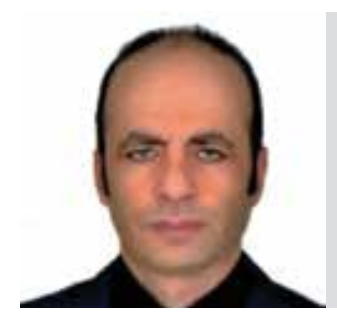

Abdurrahim Akgündoğdu was born in Bingöl in 1975. He received his B.Sc. and M.Sc. degrees in Electrical and Electronics Engineering and Biomedical Engineering from İstanbul University in 1995 and 2003, respectively. He received his Ph.D. degrees in Biomedical Engineering from İstanbul University in 2003 and 2010. He received the title of assistant of professor in 2014 in Turkey. Since 2000, he is working in Electrical-Electronics Engineering Department at İstanbul University, Turkey. His research interests are artificial intelligence, neural networks, automation, fuzzy logic.

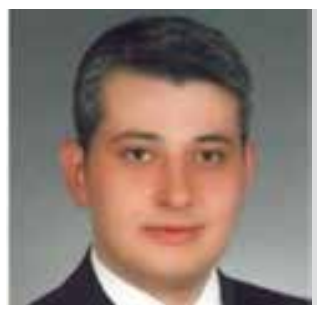

Hasan Tiryaki was born in Denizli in 1980. He received his B.Sc. and M.Sc. degrees in Electrical and Electronics Engineering from Kırıkkale University in 2002 and 2005, respectively. He received the title of assistant of professor in 2016 in Turkey. Since 2012, he is working in Electrical-Electronics Engineering Department at İstanbul University, Turkey. His research interests are railway systems, control systems, automation, power generation, transmission and distribution. 